\title{
Numerical Simulation of the Fractal Fractional Reaction Diffusion Equations with General Nonlinear
}

\author{
Khaled Mohammed SAAD ${ }^{1}$, Khaled M Saad ${ }^{2,3}$, and Manal Alqhtani \\ ${ }^{1}$ Affiliation not available \\ ${ }^{2}$ Department of Mathematics, College of Sciences and Arts, Najran University \\ ${ }^{3}$ Department of Mathematics, Faculty of Applied Science, Taiz University
}

December 14, 2020

Hosted file
Paper.pdf available at https://authorea.com/users/377697/articles/497780-numerical-
simulation-of-the-fractal-fractional-reaction-diffusion-equations-with-general-nonlinear 